\title{
Vitamin D, Obesity and COVID-19: A Gap
}

\author{
Hoang Anh Nguyen ${ }^{1}$ \\ ${ }^{1}$ University of Stirling
}

May 13, 2020

\begin{abstract}
Thousands of people across many nations lost their lives due to COVID-19. This disease is caused by a novel coronavirus named SARS-CoV-2. Besides, we always have another massive threat. It is obesity, which causes about 2.8 million deaths each year across the globe. This pandemic has just highlighted obesity and its related complications. Evidence shows that obesity is likely to cause the development of vitamin D deficiency. Moreover, inadequate Vitamin D level is independently associated with the aged and other diseases. To date, there is still no specific treatment or prevention for the SARS-CoV-2. Emerging evidence indicates that vitamin D has potential roles in the immune response against enveloped viruses including SAR-CoV-2. Optimal dosage is probably determined by the vitamin D receptor gene polymorphism. The likelihood that vitamin D may offer a potential strategy against COVID-19 should be taken into account.
\end{abstract}

\begin{abstract}
Affiliation:
University of Stirling, United Kingdom

*Correspondence to: hoang.anh.nguyen@stir.ac.uk
\end{abstract}

Keywords: COVID-19, Vitamin D, Obesity and VDR gene polymorphism

COVID-19 caused thousands of deaths in the world. This global pandemic has significantly interrupted trade, business, and education. COVID-19 disease is caused by a novel coronavirus named SARS-CoV-2. The pandemic is caused by coronaviruses is not new during the last 20 years. Between 2002 and 2003, its sister, SARS-CoV-1, killed hundreds of people. An important lesson from these outbreaks is that different human populations showed disparities in susceptibility to these viruses. There is also a different death rate between women and men. Moreover, young, healthy people also died of COVID-19 although this disease was previously thought for the elderly or those with pre-existing medical conditions such as obesity or diabetes. A question as to whether or not there is a common feature among different human populations.

Epidemiological studies currently estimate that at least one billion people with vitamin D deficiency (1), which is common with the elderly, but it is also associated with those, regardless of ageing, underlying medical conditions including obesity. To date, evidence demonstrated that people with obesity may lead to the development of vitamin D deficiency (2). An early report of the Intensive Care National Audit and Research Centre revealed 75\% of patients with severe COVID-19 symptoms were overweight or obese (3). "It seems likely that the increased prevalence of obesity in Italy older adults compared to China may account for the differences in mortality between the two countries", William Dietz and his colleague said (4). According to the Worth Health Organisation' s classification, you are overweight if your body mass index (BMI) is equal to or more than 25. BMI is "a person's weight in kilograms divided by the square of the person's height in meters $(\mathrm{kg} / \mathrm{m} 2)$ ". Based on WHO-BMI classification, about $39 \%$ of adults in the world are overweight (5). People with higher BMI are also at increased risk of various diseases such as diabetes and heart diseases. Notably, 
studies demonstrated that obesity is strongly associated with an impaired immune system and severe risk of infections, but the mechanisms involved remain unknown(6). It is hypothesised that Vitamin D receptor gene polymorphism is responsible for the susceptibility to infections including COVID-19 among overweight or obese people.

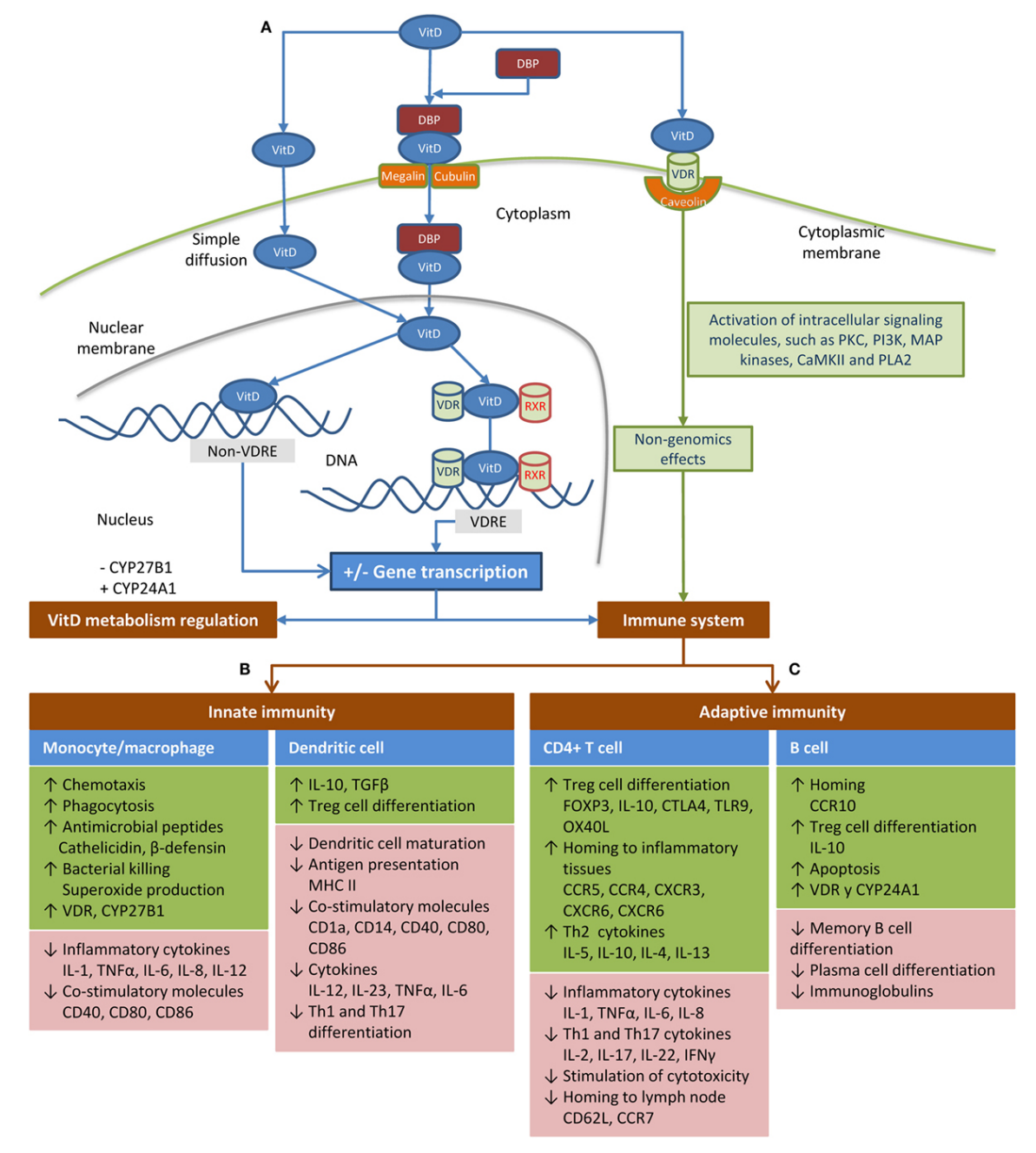

Figure 1: Schematic of mechanism of action of vitamin D in the body (adapted from Jiménez-Sousa et al. 2018)

Vitamin D not only is well-known as a sunshine vitamin for bone health but also is essential for non-bone cells including immune cells, as shown in Fig.1 $(7,12)$. Besides, Vitamin D can regulate anti-inflammatory responses by inhibiting pro-inflammatory cytokines. Cytokine storm is considered as a deadly disaster in response to SACR-CoV-2 infection and/or secondary infection because they can damage multiple organs and lead deaths (15). Vitamin D has also been well-reported as part of the potential process of fighting many infections including Tuberculosis, HIV, hepatitis $\mathrm{C}$ virus, bacterial vaginosis and colds and flu. Vitamin $\mathrm{D}$ receptor on the plasma membrane of immune cells regulates the signalling pathways of vitamin $\mathrm{D}$ in the immune response. There are six identified major VDR gene polymorphisms including Cdx, A1012G, FokI, BsmI, ApaI and TaqI (8). Some ongoing studies also explored the susceptibility to coronavirus of an individual is possibly depended by Vitamin D receptor genes relating to our immune responses against 
the virus differ between individuals. For example, immune cells called macrophages play an essential role in immune responses to viral infections. In particular, activated macrophages may intracellularly produce cathelicidin against viruses. Evidence shows Vitamin D is like the key that fits in the lock as the VD receptor on the plasma membrane of macrophages and turns it to open the door and activate these macrophages (9). Once activated, they increase the production of cathelicidin to fight the virus. A review article by William Grant and colleagues supposed that vitamin D probably reduces the risk of infectious diseases, including COVID-19, and minimize relevant deaths (10). An optimal Vitamin D level for an individual in a reduction of the infection remains unclear. The answer is probably determined by the VDR gene polymorphism. This might reflect the individual difference in the immune response as well as the effectiveness of vitamin D consumption. In a recent article published by Hoang Anh Nguyen, VDR gene polymorphisms particularly Fokl should be taken into consideration for COVID-19 and vitamin D's antimicrobial strategy (11). A study by Marina Laplana and colleagues demonstrated that the Fokl is significantly associated with the susceptibility to enveloped virus infection (8). Notably, FokI is also related to obesity(7).

Despite the promising effects of vitamin D, few ongoing studies have examined the preventative and therapeutic effect of vitamin D on COVID-19. An ongoing trial by Cédric Annweiler and colleagues (2020) is investigating the effect of high dosages of Vitamin D supplementation of 400,000 IU in a single oral dose on the elderly aged 70 and above in France, compared with standard dosages of 50,000 IU (13). In another trial by Manuel J Castillo and co-workers (2020), the COVID-19 patients with mild symptoms in Spain will receive a standard medical treatment incorporating Vitamin D supplementation of 25,000 IU(14). To our knowledge, no studies explore the precise dosages of vitamin D on COVID-19. Understanding genetic susceptibility to SAR-CoV-2 is challenging, but it has the potential to fill the gap of knowledge between the stratification of patients and personalised treatment. Thus the governments, researchers and consumer genomics labs across the globe should work on further vitamin D and COVID-19 study to figure out a bigger picture on precision strategy. It is a possibility that the VDR gene polymorphisms, probably FokI, may support a personalised treatment for COVID-19. Ethical issues and confidential relating to genetic data sharing should be carefully taken into account.

\section{Disclosure statement}

No specific funding or conflicts of interest relating to this work were reported.

\section{References}

1. R. Nair, A. Maseeh. Vitamin D: The "sunshine" vitamin. J Pharmacol Pharmacother . 3, 118-126, (2012) Abstract/FREE Full Text

2. K. S. Vimaleswaran, D. J. Berry, C. Lu, E. Tikkanen, S. Pilz, L. T. Hiraki, J. D. Cooper, Z. Dastani, R. Li, D. K. Houston, A. R. Wood, K.I. Michaëlsson, L. Vandenput, L. Zgaga, L. M. Yerges-Armstrong, M. I. McCarthy, J Dupuis, M. Kaakinen, M. E. Kleber, K. Jameson, N. Arden, O. Raitakari, J. Viikari, K. K. Lohman, L. Ferrucci, H. Melhus, E. Ingelsson, L. Byberg, L. Lind, M. Lorentzon, V. Salomaa, H. Campbell, M. Dunlop, B. D. Mitchell, K. Herzig, A. Pouta, A. Hartikainen, E. A. Streeten, E. Theodoratou, A. Jula, N. J. Wareham, C. Ohlsson, T. M. Frayling, S. B. Kritchevsky, T. D. Spector, J. B. Richards, T. Lehtimäki, W.H. Ouwehand, P. Kraft, C. Cooper, W. März, C. Power, R. J. F. Loos, T. J. Wang, M. Järvelin, J. C. Whittaker, A. D. Hingorani, E. Hyppönen. Causal Relationship between Obesity and Vitamin D Status: Bi-Directional Mendelian Randomization Analysis of Multiple Cohorts. PLOS Medicine . 10(2), e1001383. (2013) Abstract/FREE Full Text

3. M. Suthar. NHS Audit Reveals Two-Thirds of Critical Coronavirus Patients Overweight. Diabetes in Control . (2020) Abstract/FREE Full Text

4. W. Dietz, C. Santos-Burgoa. Obesity and its Implications for COVID-19 Mortality. Obesity (Silver Spring) , (2020). Abstract/FREE Full Text

5. World Health Organization Fact Sheet Obesity and Overweight. 2017 Abstract/FREE Full Text

6. R. Huttunen, J. Syrjanen. Obesity and the risk and outcome of infection. International Journal of Obesity . 37, 333-340. (2013) Abstract/FREE Full Text

7. P. Sakharkar, S. Deb, D. Vu. Vitamin D Receptor (VDR) Gene Polymorphism: Implications on 
Non-Bone Diseases. J Basic Clin Pharma . 8, S06-S10. (2017)Abstract/FREE Full Text

8. M. Laplana, J. Luis, R. J. Fibla. Vitamin D Receptor polymorphisms and risk of enveloped virus infection: A meta-analysis. Gene . 678, 384-394 (2018) Abstract/FREE Full Text

9. A.S. Vanherwegen, C. Gysemans, C. Mathieu. Regulation of Immune Function by Vitamin D and Its Use in Diseases of Immunity.Endocrinol Metab Clin North Am . 46(4),1061-1094 (2017) Abstract/FREE Full Text

10. W.B Grant, H. Lahore, S. L. McDonnell, C. A. Baggerly, C. B. French, J. L. Aliano, H. P. Bhattoa. Evidence that Vitamin D Supplementation Could Reduce Risk of Influenza and COVID-19 Infections and Deaths. Nutrients . 12, 988. (2020) Abstract/FREE Full Text

11. Hoang-Anh Nguyen. Vitamin D and SARS-CoV-2. Swiss Medical Weekly . (2020) Abstract/FREE Full Text

12. M. A. Jimenez-Sousa, I. Martinez, L.M. Medrano, A. Fernandez-Rodriguez, \& S. Resino (2018). Vitamin D in Human Immunodeficiency Virus Infection: Influence on Immunity and Disease. Frontiers in immunology, 9, 458. Abstract/FREE Full Text

13. C. Annweiler et al. (2020) COvid-19 and Vitamin D Supplementation: a Multicenter Randomized Controlled Trial of High Dose Versus Standard Dose Vitamin D3 in High-risk COVID-19 Patients (CoVitTrial). ClinicalTrials.gov [Ongoing] Abstract/FREE Full Text

14. M. J Castillo et al. (2020) Vitamin D on Prevention and Treatment of COVID-19 (COVITD-19). ClinicalTrials.gov [Ongoing] Abstract/FREE Full Text

15. M.Z. Tay, C.M. Poh, L. Renia, et al. The trinity of COVID-19: immunity, inflammation and intervention. Nat Rev Immunol (2020). Abstract/FREE Full Text 